\title{
A Correlative Analysis of Machining Parameters with Surface Roughness for Ferrous and Non- Ferrous Alloy Materials
}

\author{
Asim M Saddiqe ${ }^{1}$, Murali R V ${ }^{2}$ \\ ${ }^{1}$ Level 4 B. Engg CAME student, Caledonian College of Engineering, Oman \\ ${ }^{2}$ Faculty, Department of Mechanical and Industrial Engineering, Caledonian College of Engineering, Oman
}

\begin{abstract}
Average Surface Roughness $\left(R_{a}\right)$ is one of the most frequently used texture parameters to define the quality of turned components. The roughness values of a turned surface much depends on cutting parameters such as cutting speed, feed rate and depth of cut. Optimization of these parameters is very important in relation to surface roughness as they reveal the best suitable conditions for the turning operation. In this project, a correlative study of machining parameters and the surface roughness for ferrous (stainless steel 304) and non-ferrous alloy (Aluminium) material is carried out. Response Surface Methodology (RSM) and Analysis of Variance (ANOVA) techniques are employed in this analysis to explain the influence of different cutting parameters on surface roughness values. The combination of optimum experimental parameters can be found by machining these ferrous and non-ferrous materials in CNC turning center and finding the least surface roughness parameters. ANOVA analysis, integrated with Design Expert software, is used to determine effective ratios of the parameters and subsequently the relationships between input parameters and their responses relationship are established. The minimum surface roughness results in reference to spindle rpm, feed rate, and depth of cut are determined and estimation of the optimal surface roughness values (Ra) for least surface roughness are the results obtained in the study. In case of stainless steel 304, optimal values of cutting speed, feed and depth of cut against the least surface roughness value of 1.33 microns are found to be $220 \mathrm{~m} . \mathrm{min}^{-1}, 0.2 \mathrm{~mm}$. rev $\mathrm{re}^{-1}$ and $0.3 \mathrm{~mm}$ respectively. In case of Aluminium, optimal values of cutting speed, feed and depth of cut against the least surface roughness value of 2.8 microns are $200 \mathrm{~m}$. $\mathrm{min}^{-1}, 0.2 \mathrm{~mm}^{\mathrm{rev}} \mathrm{v}^{-1}$ and $1.15 \mathrm{~mm}$ respectively. These results reaffirm that RSM and ANOVA techniques are useful and efficient in achieving optimal set of machining parameters for select ferrous and non-ferrous materials in correlating the surface finish values.
\end{abstract}

Keywords-Response Surface Methodology, Analysis of Variance, Computer Numerical Control, Surface Roughness, Machining Parameters.

\section{INTRODUCTION}

Surface roughness is defined as the shorter frequency of real surfaces relative to the troughs. When machined parts are looked at carefully, their surfaces are found to embody a complex shape made of a series of peaks and troughs of varying heights, depths, and spacing. Surface roughness is greatly affected by the microscopic asperity of the surface of each part. Surface roughness for a machined component depends on the following factors:

- $\quad$ cutting speed selected

- depth of cut set

- $\quad$ feed rate set

- $\quad$ spindle speed set

- type of coolant used

- type of cutting tool used

- Type of material being machined etc

In recent times, industrial manufacturing process has become more advanced and they are trying to produce the products at lesser cost and enhanced quality. Surface roughness is the most important factor which can increase the quality of machine components. Influence of each factor aforementioned on surface roughness can be experimentally predicted by using Response Surface Methodology (RSM) method supported by Analysis of Variance (ANOVA) technique. This experimental work is carried out on a CNC turning center in Caledonian College of Engineering. The experimental results help to predict the most optimal cutting parameters to achieve the least surface roughness values so that reliability, quality and longevity of the product are ensured at minimum product cost. This paper aims at analyzing and investigating the different machining parameters such as cutting speed, feed rate and depth of cut and their effect on surface roughness values for different ferrous alloy and non-ferrous alloys using RSM and ANOVA techniques and to make a comparative study on the same. Investigation results in proposing a new scope of improvement for industrial applications. This is a thrust area for new researchers to work 
on and produce some productive results which will benefit the production industries by choosing correct set of machining parameters.

\section{BACKGROUND STUDIES}

In production industries, manufacturing process plays a vital role in achieving maximum productivity and quality of products. This manufacturing process can be of two type secondary and primary process. Secondary process contains machining while primary manufacturing contains Forging, Welding, and Casting etc. For calculating the total production time for a particular product, actual machining time and materials removal rate (MRR) are important variables and these values determine the average surface roughness $\left(\mathrm{R}_{\mathrm{a}}\right)$ values. Mild steel (EN8) and Aluminum are the work materials used in this study. Mild steel materials are frequently used for making shafts, connecting rods, bolts, hydraulic rams, screws and many machining parts. Its hardness ranges from 201-255HBand its major elements of composition are as follows: Carbon (0.36-0.44\%), Silicon (0.1-0.4\%), Phosphorus (0.05\%) Manganese (0.60-1.00\%) and Sulphur (0.05\%) (Ganesh, et al., 2014).

Machine tool technology is very important for all sectors of economy as it produces all tools which generate production. Experimental Investigation on the mild steel has been carried out for turning operation in a lathe machine and it is concluded that RSM technique is giving better results than the Taguchi technique. Surface roughness plays an important role in determining the quality of products which in turn implies that the cutting tool wear and material removal rate also have an effect on the quality of the product as demonstrated subsequently by Subhajit \& Mukherjee (2014).

In another study by Qureshi et al. (2015), P20 steel is used for optimization process for moulds and the cutting tool is TiN coated tungsten carbide. The methodology used for this work is Taguchi method. Taguchi method studies the parameter space in limited experiments by using orthogonal arrays. For measuring surface roughness Mitutoyo Surftest SJ-201P a surface roughness tester is used. The parameters which are analyzed are Spindle Speed $(\mathrm{m} / \mathrm{min})$, Feed rate $(\mathrm{mm} / \mathrm{rev})$, Depth of Cut (mm), and $\operatorname{Ra}(\mu \mathrm{m})$.

This study on AISI P20 steel carried out and it gives away the following outcomes:

- For high speed CNC turning, the recommended optimum parameters for surface roughness are combinations of 0.610, 0.240 and 0.4943 .

- It can be determined that for the optimum results the combination of and a middle value of depth of cut $0.1 \mathrm{~mm}$, low level feed of $(0.1 \mathrm{~mm} / \mathrm{rev})$ and the high level of cutting speed $(200 \mathrm{~m} / \mathrm{min})$ are best. In the study Taguchi method is used optimize of AISI P20 steel in high speed CNC turning conditions. The optimization is carried out through experiments by using different parameters like speed, feed, and depth of cut (Qureshi et al., 2015).

Rao et al., (2014) demonstrated that in doing experiments with Niobium alloy C-103, the response surface analysis technique contains (i) Box-Wilson Central Composite Design (CCD) method and (ii) Box-Behnken Design (BBD). Both methodologies need a quadratic relationship between the responses and experimental factor. In the present attempt, CCD is chosen and straight turning process is considered on CNC lathe machine. ANOVA is also used to control the working ranges of parameters which show response curves. The parameters which are analyzed are Spindle Speed $(\mathrm{rpm})$, Feed $(\mathrm{mm} / \mathrm{rev})$, Depth of Cut $(\mathrm{mm})$ and Surface Roughness $(\mu \mathrm{m})$.This study has shown that in turning operation for Niobium alloy, the values of parameters obtained are depth of cut $=0.37 \mathrm{~mm}$, feed $=0.15 \mathrm{~mm} / \mathrm{rev}$ and cutting speed $=84.32 \mathrm{~m} / \mathrm{min}$ in order to minimize the cutting force. The optimization is carried out through experiments by using different parameters like speed, feed, and depth of cut. It is concluded that the greatest effect on surface roughness is cutting force which is realized through depth of cut. If the depth of cut is increasing then cutting force will also increase.

In this paper, several impactful factors effecting surface roughness values of the component are considered for optimization process. This process is suitably developed by implementing RSM/ANOVA techniques to achieve a set of optimal values for achieving least surface roughness values which is very important from the industrial point of view.

\section{MATERIALS \& METHODS}

A typical ferrous (stainless steel 304 grade) and non-ferrous material (Aluminum) are selected for the purpose of study. Stainless steel is the combination of different metals making it with very handful properties. Type 304 is the most extensively used austenitic stainless steel, because of its composition in which $18 \%$ chromium and $8 \%$ Nickel. It has good strength and strong resistant to corrosion and has good welding and forming properties as well as has good draw ability. It can be made into different shapes without annealing. Key mechanical and physical properties are presented in Table 1 while chemical composition is presented in Table 2 for reference. 
TABLE 1

Key Properties OF 304 STEEL

\begin{tabular}{|c|c|}
\hline PROPERTY & VALUE \\
\hline Density & $4500 \mathrm{~kg} / \mathrm{m}^{3}$ \\
\hline Specific Heat & $0.50 \mathrm{~kJ} / \mathrm{kg}-\mathrm{K}$ \\
\hline Thermal Conductivity & $16.2 \mathrm{~W} / \mathrm{m}-\mathrm{k}$ \\
\hline Modulus of Elasticity & $193 \mathrm{GPa}$ \\
\hline Melting Point Range & $1399{ }^{\circ} \mathrm{C}-1454^{\circ} \mathrm{C}$ \\
\hline Ultimate Tensile Strength & $510-620 \mathrm{MPa}$ \\
\hline
\end{tabular}

TABLe 2

Chemical Composition Of 304 STEel

\begin{tabular}{|c|c|}
\hline ELEMENT & TYPE 304 (\%) \\
\hline Carbon & 0.08 max. \\
\hline Manganese & 2.00 max. \\
\hline Phosphorus & 0.045 max. \\
\hline Sulfur & 0.03 max. \\
\hline Silicon & 0.75 max. \\
\hline Chromium & $18.00-20.00$ \\
\hline Nickel & $8.00-12.00$ \\
\hline Nitrogen & 0.10 max. \\
\hline Iron & Balance \\
\hline
\end{tabular}

Type 304 stainless steel is used in the food industry. This is suitable for distilling, milk processing as well as in storage tanks, fermentation vats, yeast pans, and pipelines. Due to its corrosion resistance ability it is used in cooking appliances, coffee pots, refrigerators, tabletops, sinks and stoves. They have also have application in the in the dyeing industry, water filtration systems, marine nuts, screws and bolts, mining equipment, heat exchangers, chemical containers, and architecture etc.

On the other hand, Aluminum is a light weight, silvery white, recyclable, strong and excellent corrosion resistant metal. It has a high thermal conductivity, is non-toxic, has low density, and can be easily cast, machined and formed. It is also nonsparking and non-magnetic. Aluminum is used in large number of products which includes airplane parts, beer kegs, window frames, kitchen utensils, foils, cans. Key mechanical and physical properties are presented in Table 3 for reference.

CNC machine which is used for this experiment is ACE Designers, Fanuc oi-Mate-TD. Key specifications of the CNC Lathe are listed below:

- $\quad$ Flat Nose $\varnothing 110 \mathrm{~mm}$ Spindle

- 8 station Bi-Directional Turret (BTP-50)

- $\quad$ Tail stock with External Rotating Center.

- $\quad$ Spindle Motor Power: $5.5 \mathrm{KW}$

- $\quad$ Spindle Speed: 50-5000 RPM

- $\quad$ Between Center Length: $200 \mathrm{~mm}$

- $\quad$ Maximum Machining Diameter: $190 \mathrm{~mm}$

- $\quad$ Standard Chuck size: $135 \mathrm{~mm}$

Mitutoyo Surftest SJ-301 is a device which is used for measuring average surface roughness of the test materials. International standards like JIS-B-061-1982, JIS-B-0601-1994, ANSI, ISO, and DIN are set while measuring the surface texture parameters. Cemented carbide tool is used for machining the materials as it has tantalum carbide (TaC), titanium carbide (TiC) or tungsten carbide (WC) as the aggregate. Here in this study tungsten carbide aggregate is used (code TNMG 160408 NN LT 10).

TABLe 3

Key Properties of Aluminium

\begin{tabular}{|c|c|}
\hline PROPERTY & VALUE \\
\hline Density & $2.70 \mathrm{~g} \mathrm{~cm}^{-3}$ \\
\hline Specific Heat & $897 \mathrm{~J} / \mathrm{kg}-\mathrm{K}^{-}$ \\
\hline Thermal conductivity & $205 \mathrm{~W} / \mathrm{m} \mathrm{K}$ \\
\hline Young's modulus & $70.3 \mathrm{GPa}$ \\
\hline Melting Point & $660^{\circ} \mathrm{C}$ \\
\hline
\end{tabular}


Therefore, in this attempt, RSM and ANOVA techniques are employed to explain the influence of different cutting parameters on surface roughness values. The combination of optimum experimental parameters can be found by machining these ferrous and non-ferrous materials in CNC turning center and finding the least surface roughness parameters. ANOVA analysis, integrated with Design Expert software, is used to determine effective ratios of the parameters and subsequently the relationships between input parameters and their responses relationship are established. The minimum surface roughness results in reference to spindle rpm, feed rate, and depth of cut are determined and estimation of the optimal surface roughness values $(\mathrm{Ra})$ for least surface roughness are the results obtained in the study.

\section{DESIGN OF EXPERIMENTS}

Design of experiments (DOE) is an efficient method to obtain the relationships between input and output in a particular process. Input is the effecting factors while output is the response of that process. It is very useful to find cause and affect relationships. In order to optimize the output this information is required to manage process inputs. Various components of DoE are listed in here.

Factors: It is the input of the process. Factors or the parameters which are affecting the process. Levels: It is the maximum and lower limit which is giving to the process. For a two level design the levels will be high and low Response: Response is the output of the experiments which gives the desired effect. An important stage of RS model generation by RSM is the planning of experiments. The parameters which are used for the experiments are cutting speed (Vc-m/min), feed (f- $\mathrm{mm} / \mathrm{rev})$, and depth of cut (d-mm) with two levels label as high and low level as depicted in Table 4.

\section{TABLE 4 \\ MaChining PARAmeters \\ (Stainless steel 304)}

\begin{tabular}{|c|c|c|c|}
\hline Name & Type & Low & High \\
\hline Cutting speed $\left(\mathrm{m}^{-m^{-1}}\right)$ & Factor & 170 & 270 \\
\hline Feed $\left(\mathrm{mm} \cdot\right.$ rev $\left.^{-1}\right)$ & Factor & 0.2 & 0.4 \\
\hline Depth of cut $(\mathrm{mm})$ & Factor & 0.3 & 2 \\
\hline
\end{tabular}

In this investigation, 17 experiments for each type of materials were conducted considering 3 cutting parameters. The generated values of the experiment performed for Stainless Steel and Aluminium are presented in tables 4 through 7 as follows.

\section{TABLE 5}

VALUES GENERATED BY ANOVA

(Stainless steel 304)

\begin{tabular}{|c|c|c|c|c|c|}
\hline \multirow{3}{*}{ Std } & \multirow{3}{*}{ Run } & Factor 1 & Factor 2 & Factor 3 & Response \\
\hline & & A:Cutting speed & B:Feed & C:Depth of cut & Response surface roughness \\
\hline & & $\mathrm{m} / \mathrm{min}$ & $\mathrm{mm} / \mathrm{rev}$ & $\mathrm{mm}$ & microns \\
\hline 6 & 1 & 270 & 0.3 & 0.3 & 2.19 \\
\hline 4 & 2 & 270 & 0.4 & 1.15 & 3.65 \\
\hline 11 & 3 & 220 & 0.2 & 2 & 1.89 \\
\hline 15 & 4 & 220 & 0.3 & 1.15 & 2.27 \\
\hline 16 & 5 & 220 & 0.3 & 1.15 & 2.41 \\
\hline 8 & 6 & 270 & 0.3 & 2 & 2.27 \\
\hline 12 & 7 & 220 & 0.4 & 2 & 3.14 \\
\hline 10 & 8 & 220 & 0.4 & 0.3 & 3.38 \\
\hline 13 & 9 & 220 & 0.3 & 1.15 & 2.41 \\
\hline 2 & 10 & 270 & 0.2 & 1.15 & 1.41 \\
\hline 9 & 11 & 220 & 0.2 & 0.3 & 1.33 \\
\hline 17 & 12 & 220 & 0.3 & 1.15 & 2.36 \\
\hline 7 & 13 & 170 & 0.3 & 2 & 2.35 \\
\hline 1 & 14 & 170 & 0.2 & 1.15 & 1.9 \\
\hline 3 & 15 & 170 & 0.4 & 1.15 & 3.07 \\
\hline 14 & 16 & 220 & 0.3 & 1.15 & 2.19 \\
\hline 5 & 17 & 170 & 0.3 & 0.3 & 2.16 \\
\hline 6 & 1 & 270 & 0.3 & 0.3 & 2.19 \\
\hline 4 & 2 & 270 & 0.4 & 1.15 & 3.65 \\
\hline 11 & 3 & 220 & 0.2 & 2 & 1.89 \\
\hline
\end{tabular}




TABLE 6
MACHINING PARAMETERS
(Aluminium)
\begin{tabular}{|c|c|c|c|}
\hline Name & Type & Low & High \\
\hline Cutting speed $\left(\mathrm{m} . \mathrm{min}^{-1}\right)$ & Factor & 170 & 0.2 \\
\hline Feed (mm. $\left.\mathrm{rev}^{-1}\right)$ & Factor & 0.2 & 2 \\
\hline Depth of cut $(\mathrm{mm})$ & Factor & 0.3 & 2 \\
\hline
\end{tabular}

\section{TABLE 7}

VALUES GENERATED BY ANOVA

(Aluminium)

\begin{tabular}{|c|c|c|c|c|c|}
\hline \multirow{3}{*}{ Std } & \multirow{3}{*}{ Run } & Factor 1 & Factor 2 & Factor 3 & Response \\
\hline & & A:Cutting speed & B:Feed & C: Depth of cut & Response surface roughness \\
\hline & & $\mathrm{m} / \mathrm{min}$ & $\mathbf{m m} / \mathbf{r e v}$ & $\mathbf{m m}$ & microns \\
\hline 6 & 1 & 270 & 0.3 & 0.3 & 2.19 \\
\hline 4 & 2 & 270 & 0.4 & 1.15 & 3.65 \\
\hline 11 & 3 & 220 & 0.2 & 2 & 1.89 \\
\hline 15 & 4 & 220 & 0.3 & 1.15 & 2.27 \\
\hline 16 & 5 & 220 & 0.3 & 1.15 & 2.41 \\
\hline 8 & 6 & 270 & 0.3 & 2 & 2.27 \\
\hline 12 & 7 & 220 & 0.4 & 2 & 3.14 \\
\hline 10 & 8 & 220 & 0.4 & 0.3 & 3.38 \\
\hline 13 & 9 & 220 & 0.3 & 1.15 & 2.41 \\
\hline 2 & 10 & 270 & 0.2 & 1.15 & 1.41 \\
\hline 9 & 11 & 220 & 0.2 & 0.3 & 1.33 \\
\hline 17 & 12 & 220 & 0.3 & 1.15 & 2.36 \\
\hline 7 & 13 & 170 & 0.3 & 2 & 2.35 \\
\hline 1 & 14 & 170 & 0.2 & 1.15 & 1.9 \\
\hline 3 & 15 & 170 & 0.4 & 1.15 & 3.07 \\
\hline 14 & 16 & 220 & 0.3 & 1.15 & 2.19 \\
\hline 5 & 17 & 170 & 0.3 & 0.3 & 2.16 \\
\hline 6 & 1 & 270 & 0.3 & 0.3 & 2.19 \\
\hline 4 & 2 & 270 & 0.4 & 1.15 & 3.65 \\
\hline 11 & 3 & 220 & 0.2 & 2 & 1.89 \\
\hline
\end{tabular}

Stainless steel and Aluminum specimens for turning operation are of diameter of 30mm and of length $100 \mathrm{~mm}$.

\section{RESUlTS AND DISCUSSION}

Surface roughness plays an important in the designing and manufacturing, if there is an improvement in surface finish values, and then the cost of manufacturing will decrease. Therefore our aim is to decrease the surface roughness values at an optimal set of machining parameters. Surface roughness is measured for select materials by using Mitutoyo SJ-301 for three different places of the material and an average has been taken into consideration. The roughness experiment results show that the minimum roughness from the stainless steel 304 machined parts is 1.33 microns while the minimum surface roughness in the Aluminium machined parts is 2.73 microns. 


\begin{tabular}{|c|c|c|c|}
\hline 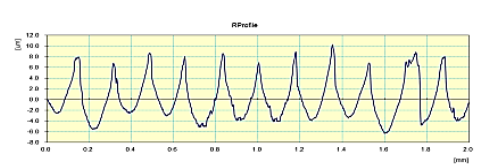 & $\begin{array}{c}\text { Exp } 7 \\
\text { Run1 } \\
\text { Ra=3.16 }\end{array}$ & 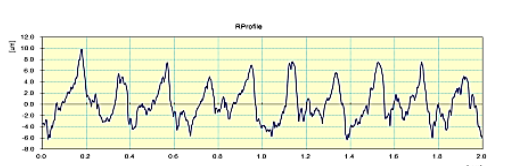 & $\begin{array}{c}\text { Exp } 4 \\
\text { Run } 2 \\
\mathrm{Ra}=2.66\end{array}$ \\
\hline$M \sqrt{N}$ & $\begin{array}{c}\text { Exp } 7 \\
\text { Run2 } \\
\mathrm{Ra}=3.05\end{array}$ & 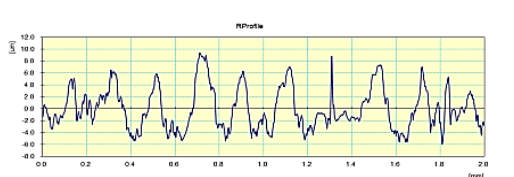 & $\begin{array}{c}\text { Exp } 4 \\
\operatorname{Run} 3 \\
\mathrm{Ra}=2.85\end{array}$ \\
\hline$\underset{n=\infty}{N \wedge N \wedge N}$ & $\begin{array}{c}\text { Exp } 7 \\
\text { Run3 } \\
\text { Ra=3.23 }\end{array}$ & 等 & $\begin{array}{c}\text { Exp } 5 \\
\text { Run 1 } \\
\mathrm{Ra}=2.72\end{array}$ \\
\hline 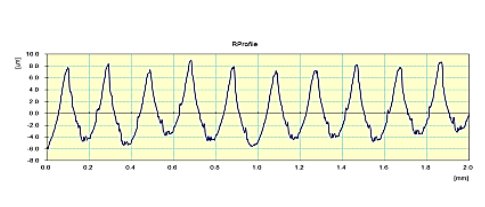 & $\begin{array}{c}\text { Exp } 8 \\
\text { Run1 } \\
\text { Ra=3.31 }\end{array}$ & 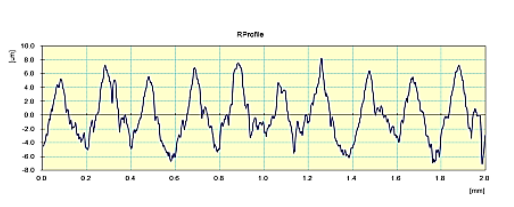 & $\begin{array}{c}\text { Exp 5 } \\
\text { Run 2 } \\
\mathrm{Ra}=2.88\end{array}$ \\
\hline$\prod_{\substack{n \\
: \infty}} \wedge \wedge \wedge \wedge \wedge \wedge$ & $\begin{array}{c}\text { Exp } 8 \\
\text { Run2 } \\
\text { Ra=3.52 }\end{array}$ & \multirow{2}{*}{\multicolumn{2}{|c|}{ Figure 2 Roughness Profile - AluminiUM }} \\
\hline FIGURE 1 ROUGHNESS P & -SS 304 & & \\
\hline
\end{tabular}

\section{CONCLUSION}

This study presents the findings of an experimental investigation into the effect of turning parameters like cutting speed, feed rate and depth of cut by turning ferrous (stainless steel 304) and non- ferrous material (Aluminium) in the CNC turning center and then checked the surface roughness values with Mitutoyo SJ-301 instrument. The effects of parameters and their correlation with the surface roughness and the optimal values have been analysed.

In case of stainless steel 304, optimal values of cutting speed, feed and depth of cut against the least surface roughness value of 1.33 microns are found to be $220 \mathrm{~m} . \mathrm{min}^{-1}, 0.2 \mathrm{~mm}$. rev ${ }^{-1}$ and $0.3 \mathrm{~mm}$ respectively. In case of Aluminium, optimal values of cutting speed, feed and depth of cut against the least surface roughness value of 2.8 microns are $200 \mathrm{~m} . \mathrm{min}^{-1}, 0.2 \mathrm{~mm}$ $\mathrm{rev}^{-1}$ and $1.15 \mathrm{~mm}$ respectively.

These results reaffirm that RSM and ANOVA techniques are capable of achieving optimal set of machining parameters for select ferrous and non-ferrous materials machining and to effectively correlate the surface finish values obtained. Therefore, it is concluded that for stainless steel 304 feed and depth of cut are major influencing factors while for Aluminium, the feed rate is the major influencing factor in order to get minimum surface finish values. The study and associated results/outcomes of the analysis would add value to the current literature available in this research domain.

Effect of machining parameters on the tribology of the machined components can be a vast area to study and investigate. In this attempt, the effects of cutting parameters such as speed, feed and depth of cut are considered and their correlation with the surface roughness are analysed and presented. Although the current approach which is used to find the optimal parameters is Response surface method and ANOVA. The optimal results are varying for surface finish and therefore there should be improved unique values for the model to get even better surface finish values in the future work. Furthermore investigation and analysis can be extended to include other mechanical properties such as fatigue and torsion etc in order to enhance the level of investigation into this effect. Finally, a number of different materials such as alloys (ferrous and nonferrous) can be subject to this kind of study in order to draw a wider analysis and conclusion by taking this work as a reference work. This can open up new fields of research for young researchers to go beyond in this field and can benefit the industry. 


\section{REFERENCES}

[1] Ganesh, N., et al., 2014. Optimization of cutting parameters in turning of EN 8 steel using response surface method and genetic algorithm. International Journal of Mechanical Engineering and Robotics Research. 3(2).

[2] Qureshi, A., et al., 2015. Optimization of Cutting parameters for Surface roughness in CNC turning of P20 steel. International Journal of Scientific \& Engineering Research. 6(12).

[3] Phogat, A., et al., 2013. Optimization of cutting parameters for turning operations based on response surface methodology. International Journal of Enhanced Research in Science Technology \& Engineering. 2(7). p. 83-89.

[4] Rao, S.K., et al., 2014. Optimization of Cutting parameters for cutting force on Turning of Niobium alloy C-103 by using Response Surface Methodology. International Journal of Innovative Science, Engineering \& Technology. 1(4).

[5] Subhajit, D, \& Mukherjee, S., 2014. Optimization of cutting parameters for improving surface roughness in turning operation using taguchi method and anova, International Journal of Research in Engineering and Technology. 3 (6). 